\title{
A Packaged Deal: Effective Support Systems for International Student Spouses
}

\author{
Kirsten A. Bilas
}

Northeastern University, United States

\begin{abstract}
Global student mobility is growing in importance as students increasingly turn their interest worldwide. International student spouses and their personal experiences is an emerging problem of practice in higher education due to their connection to international student retention rates. In particular, what support systems are provided to this demographic is especially important. Interpretive Phenomenological Analysis (IPA) was used to examine international student spouses' perception of support services at an urban private institution of higher education in the United States. A qualitative approach addressed the following research question: What role do international student spouses perceive institutions of higher education have in terms of offering support services? This study focused on five international student spouses who came to the United States on F2 dependent visa status.
\end{abstract}

Keywords: international higher education, university support services, international student spouses

\section{Introduction}

For the first time in decades, new international student enrollment in American institutions of higher education has decreased (Institute of International Education [IEE], 2018). In spite of this, the demographic still is considered an integral part of higher education systems (Bordoloi, 2015). While international students benefit greatly during their time abroad, not much has been understood about the same for spouses (Bordoloi, 2015; De Verthelyi, 1995) lending many of them to be considered the "invisible population" (Teshome \& Osei- 
Kofi, 2012). IEE's “Open Doors” report (2018) does not mention international student spouses yet they have been found to be significant to higher education (Lin, 2018). With so little statistical information about this demographic, it is hard to determine what percentage of international students bring spouses with them in addition to knowing the exact number of these spouses. However, previous literature (Lei et al., 2015; Lin, 2018; Teshome \& Osei, 2012) has shown the link between international student success and retention rates and the successful acculturation of international student spouses. Emotional support and encouragement were found by Lynch (2008) to be major factors in student success as many international students relied on emotional support from their spouses throughout their program. However, international student spouses often emphasized lack of institutional support systems (Campbell \& Prins, 2016) and many found themselves oftentimes left alone for the majority of the day (Myers-Walls et al., 2011). Because of their direct link to international student retention (Martens \& Grant, 2008), it is important to learn more about international student spouses as well as how institutions can better support them.

While the majority of research in regards to international student spouses have been focused on acculturation issues (Bordoloi, 2015; Campell \& Prins, 2016; Chen, 2009; Cho et al., 2006; De Verthelyi, 1995; Kim, 2006; Kim, 2012; Lei et al., 2015; Lin, 2018; Marten \& Grant, 2008; Myers-Walls et al., 2011; Teshome \& OseiKofi, 2012; Zhang et al., 2011), none has focused specifically on support systems institutions could provide to this demographic. The purpose of this study was to investigate individual experiences of international student spouses to understand their perceptions of university support systems by employing Interpretative Phenomenological Analysis (IPA). This study bridges this gap in literature by focusing on the specific support systems international student spouses desired and how institutions can implement such services by answering the research question: What role do international student spouses perceive institutions of higher education have in terms of offering support services?

\section{Methodology}

For this study, the researcher wanted to know what role do international student spouses perceive institutions of higher education have in terms of offering support services. The international program office at the research site sent out an email on behalf of the researcher with 
information on the study and requesting spouses to contact the research directly in order to take part. Five participants took part in semi-structured interviews lasting from 30 minutes to an hour about their experiences with university support systems while in F2 dependent visa status. Interviews were transcribed, coded, and analyzed by the researcher with transcripts approved by each participant. All participants were married to current international students enrolled at an urban institution of higher education in the New England region of the United States, and had been in F2 dependent visa status. F2 status meant they are a dependent of an international student who was designated as F1 visa status (US Department of State, 2019). Two participants were from China, one from Egypt, one from India, and one from Turkey. This small pool allowed the researcher to learn more about each spouse's unique experiences with dealing with support services at the institution. Three out of the five participants had switched their visa status from dependent to student at the time of the interview.

\section{Theoretical Framework}

Acculturation theory is a framework important to many researchers who wish to study international education. It was particularly useful when trying to learn more about the cultural experiences faced by spouses of international students while adjusting to life in the United States. John Berry's (1992) model in regards to acculturation theory looks at the phenomenon in a holistic way instead of looking at one specific component which benefits this study.

The bidimensional model of acculturation by Berry (1992) worked well with this study as it involved international students and their spouses. Since the spouses of international students were oftentimes in touch with family and friends still in their home country (Park et al., 2014), it was easy to assume they would still hold on to cultural aspects of their homeland and their new country for the duration of their stay. This specific acculturation model allowed the researcher to take those experience into account while collecting data.

Acculturation theory shaped the interview questions for this research project in various forms. First of all, the questions were formed to focus directly on the participants' experiences of 
coming to the United States. By focusing the questions on their own unique experiences, information could then be provided to institutions of higher education to help better prepare both the institution and the international program offices in general in how to better recruit and retain international students and their families. This could include the creation of specific procedures and programs relating directly to this demographic.

\section{Procedures}

Interpretative Phenomenological Analysis (IPA) was chosen as the methodology for this research. This methodology focused on perspective, context, and interpretation. IPA was defined by Smith (2004) as aiming "to explore in detail participants' personal lived experience and how participants make sense of that personal experience" (p. 40). In addition, the focus of using this unique methodology was for those taking part in the study to create an understanding of each individual experience (Smith et al., 2009). Pietkiewicz and Smith (2014) regarded the primary concern for researchers using IPA was to gather rich, detailed first-person accounts of unique experiences. Data was collected through in-person interviews, the most popular way for this methodology (Pietkiewicz \& Smith, 2014). It was important to work with the international programs office to send an email to the international student population at the research site to get in touch about the study. Once spouses had shown interest, interview requests were made.

Questions were open-ended and semi-structured in format to allow informative responses. This allowed participants and researcher to engage in meaningful dialogue in real-time (Pietkiewicz \& Smith, 2014). Participants signed consent forms prior to interview which lent credibility, a major component of IPA (Lincoln \& Guba, 1985). Interviews were audio recorded and transcribed prior to analysis. After the completion of the transcriptions of interviews, participants were provided with a copy to review for accuracy and clarification purposes. During the analysis process, coding was conducted through recognition of developing emerging themes and subthemes from the transcripts.

\section{Data Analysis}


According to Smith et al. (2009), there were four unique characteristics of IPA when it came to data analysis. The characteristics were movement from unique experiences from one participant to what is shared among all participants of the study, how the experience is described moving to how the same experience could be interpreted, commitment by the researcher to attempt to understand the point of view of each participant, and using a psychologically focused context when looking at how participants make meaning of their experiences (Smith et al., 2009). After the completion of all interviews, the audio was then transcribed into a word document format for review. For the purpose of this research, the interview audio was transcribed using a program called Temi. Once in word format and approved by the participant for accuracy, the documents were then reviewed to begin the initial coding process. It was important for the researcher to conduct the transcription and initial coding as soon as possible upon the completion of each individual interview. On average the transcription was completed and emailed to the participant within a week of the interview.

Reading the completed transcripts was considered the next step of the process. This was the first step of the analysis process of the study and is done to make sure the participants were the focus (Smith et al., 2009). The initial readings allowed the researcher to pick up on unique experiences and their importance to the study. Once all of the transcripts had been read through and noted, the second step of analysis began. The transcripts were reread, this time looking for more meaning behind the interview and themes were noted. This was known as coding. The method of coding was used while analyzing data collected from the proposed research study. Specific codes were created by the researcher after the interviews had been transcribed in order to identify various themes which occurred throughout the study. After each of the interview transcriptions initially had been coded, a second review of the transcripts occurred to allow for the possibility of sub-codes to be created. These codes, therefore, began to show common themes throughout each individual interview conducted.

\section{Findings}


Interviews provided detailed experiences from spouses allowing key themes to emerge.

These included need for better communication, more opportunities for integration into the campus community, creation of on-ground support, in addition to new findings which had not been found in previous literature.

\section{Need for Better Communication}

Participants noted consistently the lack of information received from the institution in regards to support services. While participants did not receive any communication from the institution, they stressed desire for that to change. During these discussions, welcome letters, email, and website communication came up as potential ways the institution could provide communication with spouses. Information was really important to the spouses as one noted "as a student you get everything [emails], but as a spouse of the student - nothing." Any type of acknowledgement from the institution was highly desired. In particular, spouses wanted more information on health care, legal support (both in terms of immigration and domestic violence), programming on campus, language programs, obtaining housing, and point of contact at the institution which they could ask questions.

Responses aligned with previous literature noting participants felt, similar to Campbell and Prin's (2016) study, a lack of institutional support. Participants felt there were no services besides providing information on obtaining visas for entry into the United States. They had to figure out information on their own which agreed with Akanawa's (2015) study in which spouses of international students were left to figure support services out without any help from institutions.

\section{More Opportunities for Integration into Campus Community}

Participants emphasized the need to integrate into the campus community. Similar to those in Campbell and Prin's (2016) study, spouses had difficulty integrating into the local community in spite of attempting to find and use community resources. In particular, participants had a hard time having conversations with native speakers due to lack of confidence in their own language skills but 
also not knowing proper cultural etiquette. This was in alignment with De Verthelyi's (1995) study which showed lack of language skills prevented social interactions.

In addition, the majority of the participants wanted to gain more information about events going on around campus. As one questioned, "Why are you not inviting the spouses? Could be educated people who are interested in seminars!" Another spouse came up with the idea being able to volunteer at such events as “because most of us, we won't just want to stay home watching videos, music, and cooking".

Another way participants noted as an opportunity for integration into the campus community was by allowing spouses to have an identification card that would show they had a connection to the institution and would allow them access to the library and events on campus. For example, one participant suggested "like the alumni cards, they're not, for example, allowed to enter the library, but they're allowed to do other stuff or they're recognized as just an, some sort of, you know what I mean. You exist."

\section{Creation of On-Ground Support}

Administrators who understood unique situations facing international student spouses was strongly desired. One participant mentioned lack of support from the international programs office but was greatly impressed with all the help received from their spouse's academic department which was similar to Blount's (2008) findings of institutional administrators made a huge difference when it came to helping spouses with cultural adjustment. All participants wanted a point of contact which they would be able to communicate with in order to gain information on various topics of importance to them ranging from acculturation issues to administrative issues. While having a designated administrator to help spouses with any concerns and questions they might have is ideal, simply having a peer mentor could do much in terms of emotional support for adjustment to their new normal. Peer mentors would be helpful as they would be able to provide guidance from a personal perspective rather than from an administrative one which could be limited.

\section{New Findings}


This study unearthed findings not previously discussed in literature. These findings included these five spouses were highly educated, needed affordable housing options, and some switched from dependent to student status to alleviate stressors.

\section{Dependents Are Highly Educated}

Participants were highly educated, included those with advanced degrees and working in high demand fields such as accounting, finance, and government affairs. One participant had their MBA and another one had a masters in engineering. Both of them had decided eventually to earn other advanced degrees in order to switch to student visa status and not remain in dependent status. One was working on another masters while the other was now in a doctorate program. They were not traditional subservient partners. Because highly educated, they were able to articulate services which would benefit them as well as provide suggestions on how the research site could implement them.

\section{Need for Affordable Housing}

Ideal housing was found to be difficult to obtain due to restrictions placed by visa status. Many participants had to live with roommates or pay more to live by themselves. This included having to live in outside the city instead of campus. On-campus couple housing also was a strong desire by participants. Most participants noted they were not prepared to deal with the high demand rental market in the area. As one noted:

Of course things are more expensive... a lot more expensive. I didn't feel like things were all set for us. I mean, like I recall my father always talking about when he got his offer to the PhD, I know that was like 25 years ago or 30 years ago... I do understand that... but he always told us that they already had the housing for married people at [the institution their father attended].

It was clear staying on campus in couples-designated housing would be ideal. While dormitory housing for international students perhaps had come up in previous literature, it has not come up when discussing needs of international student spouses.

\section{Switching from Dependent to Student Status}


Three participants ended up switching from dependent to student status. It is important to note all made the change in visa status not to further their education, but to alleviate stress restrictions had put them under. One of the participants entered a doctorate program purely to get a student visa. They had no intentions of earning a doctorate and had wanted to be a consultant. However, they could not handle the limitations and stressors under the dependent visa so they ended up applying and being accepted into a program to change status. All three participants received no information on how to switch their visa status. Participants would have liked to know how to switch status if one had decided to enroll as a student. Many did not know switching their visa status could be an option and would provide more freedom than under dependent visa status.

\section{Recommendations}

The study provided a wealth of knowledge on how international student spouses perceived support services at a specific institution. Creation of a designated institutional administrator, designated campus housing, and identification card would greatly benefit spouses and be implemented without major issues.

\section{Designated Institutional Administrator}

One idea was designating an administrator as a point of contact for international student spouses. They should be housed in the international programs office and primarily focus on working with international student spouses. However, the institution might not have financial resources or need for a full-time administrator as such information was not available. In this case, the duty could be assigned to an existing departmental administrator.

Assessing needs of international student spouses would be imperative to this role. The administrator would be in charge of creating an assessment plan to help update information international student spouses would need communicated to them. They would also be in charge of creating support services such as volunteering, mentorship, and social offerings. This position should be looked at as a voice for these spouses and fight for their inclusion when dealing with issues on an institutional level and would be a direct line of communication between the institution and the 
spouses. This administrator could also help students navigate the difficult legal system if needed. For instance, as one participant articulated, spouses might need help switching their visa status from dependent to student, or might need information on how to obtain a divorce or protection due to domestic violence issues which they considered a common issue for international students and their spouses.

\section{Couple Designated Campus Housing}

Housing was a particular struggle due to financial costs of obtaining housing and secondly, the unavailability of couples designated on-campus housing. One participant was shocked to find out couples housing was not available as options had been provided other places. While the institution does provide housing for students, those who were married were not allowed to take advantage of this service. A portion of available dormitory space should be designated for married couples. The institution required first and second year undergraduate students to live on campus in dormitories. Releasing second year students from the requirement of living on campus could open dormitory space for the spouses and allow traditional undergraduate students more flexibility in their housing options.

\section{Identification Cards}

One of the most important ways institutions can create a sense of community with international student spouses is by creating a spousal identification card. Most institutions provide identification cards for their alumni to use after graduation. Something similar could easily be made available to spouses. This card would allow spouses to feel like they are part of the campus community and allow them to easily integrate into the area.

The spousal identification card would allow international student spouses access to the institution's library with ease. In addition, this identification card would make it easier for them to attend other events, such as concerts, plays, and seminars, on campus without issue. The spouses could use the card in order to get student discounts as well whether on campus or off campus to events such as museums and concerts. Spouses could even use the card to gain access to the 
campus gym if they agree to pay a monthly or semester based membership fee. This way the institution could make some additional money by the increased revenue from the gym, while allowing the spouses to stay together when using facilities.

Such identification card would also come in handy to those spouses who opt to take advantage of on campus couple housing once such is enacted. These cards would allow international student spouses access to the dormitory buildings where their housing is located. Security is an important issue in large cities such as where this institution is located. Spousal identification cards would provide an extra layer of security by only allowing those who should be in the building instead of having to wait to be let in.

Lastly, the spousal identification card could allow spouses to take advantage of some of the services already being offered at the institution, but at a limited capacity. For instance, they could be able to join social groups on campus whether they are to practice their English language skills, social networking, or just personal passions. By having the identification card, the support services at the institution knows they are providing information to a spouse of a current student and not someone who found their way to campus trying to take advantage of services.

\section{Discussion}

The main goal of this research was to gain information on international spouses' experiences with support services at institutions of higher education. The findings from this research were interesting because it gives a clearer picture how international student spouses perceive institutional support services and the duty institutions have to provide them these services. In particular interest was that this sample showed spouses were just as educated and ambitious as their student partners. They were not traditional home-makers and wanted to be involved in the campus community and longed for some sort of connection to the institution. The fact the majority of the participants ended up enrolling in advanced education programs in order to relieve stressors their dependent visa status had put on them shows while the institution was providing adequate 
services to their international student population, these services were not being reached to the spouses.

Participants were especially eager to offer suggestions on how the institution could better support them during their time in the United States. Because they were highly educated already, they knew what services would be best to help them with acculturation and provided detailed ways services could be altered to improve. On the other end, they also knew and recognized that they should not receive every single service being offered to students, such as access to classrooms and courses, but felt they should be able to attend student events such as seminars

The implications are massive when dealing with spouses of international students as well as the field of international education as a whole. Since this is still a relatively new research area in the field, the more information studies can bring to the surface, the better off institutions of higher education will be with preparing to deal with this underserved demographic. This means both administrators and faculty in the field of higher education will benefit from It will also allow for other scholar-practitioners who might not originally be considering going into the field, develop interest in conducting their own research projects to help further understanding of the topic. The more information coming from research studies will only lead to improvement of any potential adjustment issues faced by international students as well as their families which then has the possibility to increase international student retention rates.

\section{Limitations}

Research studies are not perfect and oftentimes have limitations to them. This study is no different. The limitations of using this theory was it focused strictly on the cultural adjustment of the subjects interviewed and did not take into effect directly any other potential overlapping themes. However, the researcher was able to make educated suggestions on what these institutions should look into doing based upon the information received from the interviews about adjustment issues of international student spouses. 
After the findings of the study, it would be important and imperative to research the effectiveness of the proposed changes to higher education institutions when it comes to better supporting the spouses of international students. This way, research can be done to show what worked and what did not work when it came to helping them adjust to life in the United States from an institutional perspective. Doing so will provide a whole other view on another important aspect of acculturation experiences.

\section{Conclusion}

Detailed data was collected from interviewing five international student spouses who took part in the study. Communication appeared to be one of the most important issues to participants. They desired any sort of information from the institution. Lack of communication was one of the reasons spouses struggled during their time on campus. Spouses were not made aware of important topics such as health care, housing, and campus events which might be of interest to them. Such information should be easily and readily available to them. As one participant noted, they felt nonexistent and the institution "did not care about F2... only money".

Need for inclusion into the campus community was another important finding. Since spouses oftentimes felt isolated, simply knowing about events such as seminars and other social programs would have made them feel more included and welcomed. Participants were highly educated and were interested in academic seminars and presentations on campus. However, due to the lack of communication from the institution, they were not made aware of such events until it was too late.

Lack of communication and inclusion for international student spouses came down to the issue there was no on-ground support. If an administrator focused on the needs of international student spouses, they would be able to develop a communication strategy in addition to creating programing to help with inclusion into the campus community. Participants noted they struggled with not knowing who to contact if they had any questions, especially in regards to health care and campus related issues. All of those issues could easily be resolved if an administrator was appointed. 
The findings showed the spouses were highly educated and wanted to take part in educational opportunities such as seminars on campus and did not only want social opportunities. Housing options was another big concern of international student spouses which had not been talked about before, including the desire to have more on campus housing designated purely for married couples. Lastly, no previous literature had brought up international student spouses had ended up switching their visa status from dependent to student status in order to gain some more freedom than their visa allowed upon arrival on campus.

\section{Recommendations for Future Research}

It is important to look into experiences of international student spouses and differences between urban and rural institutions in terms of support services as this study focused on the experiences of those related to a private urban institution in the United States. Researchers should take a look at same sex marriages or male spouses in particular. The majority of available literature has information from female spouses in heterosexual relationships. With growing acceptance of same-sex marriages, it will be important to focus on support services which could be offered to international student spouses in the LGBTQ community. In addition, traditionally available research has not strictly looked at male spouses and the international education field could benefit from looking into their experiences as well. This could be due to the fact many might not wish to participate, which is what occurred in this particular research study.

\section{Author Note}

Kirsten A. Bilas, Ed.D. is an administrator at Northeastern University in Boston, Massachusetts. Her research interests includes support systems for international students and their families as well as student experiences in international higher education programs. She has over a decade of experiences working in international higher education with both study abroad and international student programs. 
Correspondence concerning this article should be addressed to Kirsten A. Bilas, Boston, Massachusetts USA. Email: k.bilas@northeastern.edu

\section{References}

Akanwa, E. E. (2015). International students in western developed countries: History, challenges, and prospects. Journal of International Students, 5(3), 271-284.

Berry, J. W. (1992). Acculturation and adaptation in a new society. International Migration, 30(1), 69-85.

Blount, L. W. L. (2008). Women administrators in distance higher education: An exploratory study. Advancing Women in Leadership, 25(1), 1-21 .

Bordoloi, S. D. (2015). "I am standing still": The impact of immigration regulations on the career aspirations of wives of international students in the USA. Journal of International Migration and Integration, 16(3), 607-624.

Campbell, K., \& Prins, H. (2016). Taking initiative and constructing identity: International graduate student spouses' adjustment and social integration in a rural university town. International Journal of Lifelong Education, 35(4), 430-447.

Chen, L.-K. (2009). Negotiating identity between career and family roles: A study of international graduate students' wives in the US. International Journal of Lifelong Education, 28(2), 211226.

Cho, K.-C., Lee, J., \& Jezewski, M. A. (2005). Korean women living in the United States as student wives. Health Care for Women International, 26(10), 897-915.

De Verthelyi, R. F. (1995). International students' spouses: Invisible sojourners in the culture shock literature. International Journal of Intercultural Relations, 19(3), 387-411.

Institute of International Education. (2018, November 13). Open doors 2018: Fast facts.

http://www.iie.org/Research-and-Insights/Open-Doors/Fact-Sheets-and-Infographics/Fast- 
Kim, J. (2012). Acculturation phenomena experienced by the spouses of Korean international students in the United States. Qualitative Health Research, 22(6), 755-767.

Kim, M. (2006). "Forced" into unpaid carework: International students' wives in the United States. In M. K. Zimmerman, J. S. Litt, \& C. E. Bose (Eds.), Global dimensions of gender and carework (pp. 162-176). Stanford Social Science.

Lei, D., Woodend, J. D., Nutter, S. K., Ryan, A. R., \& Cairns, S. L. (2015). The forgotten half: Understanding the unique needs of international student partners. Journal of International Students, 5(4), 447-458.

Lin, H.-F. (2018). The "invisible" group: Acculturation of international women partners on United States campuses. Journal of Student Affairs Research and Practice, 55(3), 334-346.

Lincoln, Y. S., \& Guba, E. G. (1985). Naturalistic inquiry. Sage.

Lynch, K. D. (2008). Gender roles and the American academe: A case study of graduate student mothers. Gender and Education, 20(6), 585-605.

Martens, V. P., \& Grant, P. R. (2007). A needs assessment of international students' wives. Journal of Studies in International Education, 12(1), 56-75.

Myers-Walls, J. A., Frias, L. V., Kwon, K.-A., Ko, M.-J. M., \& Lu, T. (2011). Living life in two worlds: Acculturative stress among Asian international graduate student parents and spouses. Journal of Comparative Family Studies, 42(4), 455.

Park, N., Song, H., \& Lee, K. M. (2014). Social networking sites and other media use, acculturation stress, and psychological well-being among East Asian college students in the United States. Computers in Human Behavior, 36, 138-146.

Pietkiewicz, I., \& Smith, J. A. (2014). A practical guide to using interpretative phenomenological analysis in qualitative research psychology. Czasopismo Psychologiczne - Psychological Journal, 20(1), 7-14. 
Smith, J. A. (2004). Reflecting on the development of interpretative phenomenological analysis and its contribution to qualitative research in psychology. Qualitative Research in Psychology, $1(1), 39-54$.

Smith, J. A., Flowers, P., \& Larkin, M. (2009). Interpretative phenomenological analysis: Theory, method and research. Qualitative Research in Psychology, 6(4) 346-347.

Teshome, Y., \& Osei-Kofi, N (2011). Critical issues in international education: Narratives of spouses of international students. Journal of Studies in International Education, 16(1), 62-74.

U.S. Department of State. (2019). Student visa. https://travel.state.gov/content/travel/en/usvisas/study/student-visa.html\#spouse

Zhang, J., Suzanna, S., Swisher, M., Fu, D., \& Fogarty, K. (2011). Gender role disruption and marital satisfaction among wives of Chinese international students in the United States. Journal of Comparative Family Studies, 42(4), 523-542. 